\title{
Prospective study of congenital heart disease in children
}

\author{
Pujitha Wickramasinghe ${ }^{1}$, Sanath P Lamabadusuriya ${ }^{2}$ and S Narenthiran ${ }^{3}$ \\ (Index words: Paucity of surgical facilities, anatomical lesions)
}

\begin{abstract}
Objective Descriptive analysis of patients with congenital heart disease.

Design Prospective study.

Setting Professorial Paediatric Unit, Lady Ridgeway Hospital, Colombo 8.

Method All patients with congenital heart disease (CHD) admitted to the Professorial Paediatric Unit at Lady Ridgeway Hospital from August 1998 to August 1999 were included in this study. Data were collected using a pretested questionnaire which was filled by one of the authors. $\mathrm{Pa}$ tients were followed up to date.

Results 102 patients, $53(52.0 \%)$ males with congenital heart disease were studied. All patients were evaluated with chest xray, ECG and 2 D echocardiography, except for two. Based on clinical and echocardiographic findings $69(67.6 \%)$ were found to have acyanotic and $33(32.4 \%)$

cyanotic heart disease; $22(21.5 \%)$ had a ventricular septal defect. Tetralogy of Fallot was diagnosed in $10(9.8 \%)$ patients and was the commonest cyanotic CHD. 52 (51.0\%) cases were detected between the ages of 2 weeks to 12 months, and $39(38.2 \%)$ were detected routinely at the postnatal examination of the newborn. Only $12(11.7 \%)$ patients underwent corrective surgery, 10 in Sri Lanka, and 2 in India. 19 children died during the study period, a case fatality of $18.6 \%$.

Conclusions Previous studies have shown that congenital heart disease accounted for between $16 \%$ to $30 \%$ of deaths in the Professorial Paediatric Unit at LRH. This is the second commonest cause of deaths in the unit. This study has revealed a high case fatality rate among the patients awaiting corrective surgery. Unless surgical care for patients with congenital heart disease in the public sector are improved, many such children will continue to die early due to lack of facilities.

${ }^{1}$ Lecturer in Paediatrics, and ${ }^{2}$ Senior Professor of Paediatrics, Faculty of Medicine, University of Colombo; ${ }^{3}$ Resident Cardiologist, Lady Ridgeway Hospital, Colombo (Revised version accepted 15 September 2000).
\end{abstract}




\section{Introduction}

Congenital heart disease is one of the commonest congenital problems seen today, incidence being about 6 108 per 1000 live births (1). Based on the crude birth rate (17.3/1000 population) (2) and population of Sri Lanka, (18 million) the prediction is that about 2500 babies to be born each year will have a congenital heart defect. The outcome of CHD depends on the severity of the lesion, associated abnormalities and the availability of diagnostic and surgical expertise. With timely diagnosis and early intervention most children could attain a near normal life span and enjoy a good quality of life, as in most developed countries.

\section{Method}

The study sample consisted of 102 patients who were admitted to the Professorial Paediatric Unit (PPU) at Lady Ridgeway Hospital (LRH) from August 1998 to August 1999 for management of the heart disease or related illness. The admissions belonged to one of the following 4 categories; direct admissions from outpatient clinics 56 (54.9\%), transfers from the other hospitals 21 (20.5\%), referrals from Professorial Obstetric Unit at De Soysa Maternity Hospital $10(9.8 \%)$, and transfers from the cardiothoracic unit at the National Hospital of Sri Lanka (NHSL) for the management of acute medical problems while awaiting surgery 15 $(14.8 \%)$

The relevant data were collected using a pre-tested questionnaire filled by one of the authors, and the patients were periodically reviewed for complications and progress of the illness. The patients were evaluated by electrocardiography (ECG), chest xray and 2D echocardiography. The final diagnoses were based on $2 \mathrm{D}$ echocardiography except in 2 patients who died before evaluation, and their diagnoses were based on autopsy.

\section{Results}

Fifty three $(52 \%)$ of the patients were males. The majority were from Colombo 30 (29\%) and Gampaha 24 (23.5\%), with Kalutara and Kurunegala districts contributing 6 patients each. The ages at which these patients with CHD presented are shown in Table 1 . Thirty nine $(38.2 \%)$ were detected either at routine examination in the neonatal period or at the child welfare clinic at 6 weeks of age.

Thirty eight $(37.2 \%)$ presented with lower respiratory tract infections (LRTI). Others presented with cyanosis, heart failure or failure to thrive. The majority $(56 \%)$ presented in infancy. The types of anatomical abnormality are in Table 2. Ventricular septal defect was the single commonest anomaly $(21.5 \%)$. The commonest complication was recurrent LRTI (40.8\%) and 35.3\% patients developed heart failure and were treated with digoxin and diuretics. There were 22 patients with associated congenital abnormalities. Eight $(7.8 \%)$ patients had Down syndrome and 3 had congenital rubella syndrome.
During the study period, only 12 (11.7\%) patients. underwent corrective surgery; NHSL (3 patients), Sri Jayawardenepura General Hospital (SJGH, 5 patients), LRH (2 patients), and 2 patients in India. Palliative surgery was carried out in 3 more patients. Table 3 gives a summary of the follow up. 19 patients died giving a case fatality of $18.6 \%$ The type of CHD in the fatal cases is shown in Table 4.

Table 1. Age at diagnosis of CHD

$\begin{array}{lc}\text { Age } & \text { Number }(\%) \\ <7 \text { days } & 31(30.4) \\ 7-28 \text { days } & 14(13.7) \\ 1-12 \text { months } & 38(37.3) \\ >1 \text { year } & 19(18.6) \\ \text { Total } & 102(100.0)\end{array}$

Table 2. Type of congenital heart disease $(n=102)$

\begin{tabular}{ll} 
Acyanotic $69(67.6 \%)$ & \\
Ventricular septal defect & $22(27.5 \%)$ \\
Atrial septal defect & $18(17.6 \%)$ \\
Patent ductus arteriosus & $7(6.8 \%)$ \\
Others & 11 \\
Complex CHD* & 11 \\
& \\
Cyanotic & \\
& \\
Tetralogy of Fallot & $10(9.8)$ \\
Total/partial APVD & $5(32.4 \%)$ \\
Transposition of great vessels & $3(2.9 \%)$ \\
Others & 6 \\
Complex CHD* & 9 \\
\hline
\end{tabular}

*more than 2 cardiac lesions

APVD (anomalous pulmonary venous drainage)

Table 3. Outcome of the children with CHD

$\begin{array}{lcc}\begin{array}{l}\text { Surgery done } \\ \text { corrective } \\ \text { palliative }\end{array} & 15 & 12^{* *} \\ \text { Followed up } & & 3 \\ \quad \text { LRH } & 65 & 26 \\ \text { NHSL } & & 17 \\ \text { SJGH } & & 20 \\ \text { Others } & & 2 \\ \text { Lost for follow up } & 5 & \\ \text { Deaths } & 19 * * & \end{array}$

** 2 died following surgery

$*$ at provincial hospitals 
Table 4. Type of lesion in the children who died of CHD

$\begin{array}{lclc}\text { Acyanotic } & 9 & \text { Cyanotic } & 10 \\ \text { VSD } & 2 & \text { Tetralogy } & 1 \\ \text { PDA } & 2 & \text { TGV } & 2 \\ \text { ASD } & 2 & \text { Total/Partial APVD } & 1 \\ \text { Mitral regurgitation } & 1 & \text { Truncus arteriosus } & 1 \\ \text { Complex lesions } & 2 & \text { Branch PAS } & 1 \\ & & \text { Complex lesions } & 4\end{array}$

APVD - anomalous pulmonary venous drainage

PAS - pulmonary artery stenosis

\section{Discussion}

At the PPU/LRH congenital heart disease was found to be the second commonest cause of death accounting for $16 \%$ to $30 \%$ of deaths from 1992 to 1999 (3). The chief contributory factors for the rate of mortality is the paucity of surgical facilities in Sri Lanka for timely correction of defects and the high cost of such surgery in the private sector.

Development and cognitive impairment have been widely reported in children with congenital heart disease, especially with cyanotic lesions. In some the impairment may be congenital and in others acquired, and therefore preventable. Feeding problems resulting in failure to thrive are common in infants and young children with $\mathrm{CHD}$, and can lead to impaired development and intellect (4). Early surgical intervention is essential for the reduction of morbidity and mortality, and improvement in the quality of life. In children with acyanotic congenital heart lesions who undergo surgical repair in infancy, the prognosis is good for further cognitive and developmental progress (4). In our series the majority of the defects are acyanotic and uncomplicated 58 (56.8\%). Uncomplicated defects when corrected at an appropriate time, restore a near normal life expectancy (2). During the last 20 years although diagnostic facilities have improved, the established cardio-thoracic units in the public sector hospitals cannot cope with the number of patients with CHD who require surgery.

It is of utmost importance that steps should be taken to improve surgical facilities further in the public sector to cater to the needs of children with CHD, the majority of whom cannot afford treatment in the private sector. The construction of a new building in the premises of LRH, provides an ideal opportunity to establish an exclusively paediatric cardio-thoracic unit in Sri Lanka, to cater to the surgical needs of children in Sri Lanka with CHD, and to train health personnel for the rest of the country.

\section{Acknowledgements}

We thank the parents of the patients for the assistance given during the study, Dr. MVC de Silva for performing the autopsies and Dr Wimal Jayantha, Director Lady Ridgeway for permission to perform the study.

\section{References}

1. Houston AB. Cardiovascular disease In: Campbell AGM, McIntosh Neil; Eds. Forfer and Arneil. Textbook of Paediatrics. 2nd ed. Churchill Livingstone; 1998: 595.

2. Annual health bulletin of Sri Lanka. Ministry of Health Sri Lanka. 1998: vi-vii.

3. Lamabadusuriya SP. High mortality from congenital heart disease, (letter to the editor) Ceylon Medical Journal, 1999; 44: 99 .

4. Wray J, Sensky T. Controlled study of preschool development after surgery for congenital heart disease. Archives of Diseases in Childhood 1999; 80: 511-6.

5. Newburger JW, Silbert AR, Buckley LP, Fyler DC. Cognitive function and age at repair of transposition of the great arteries in children. New England Journal of Medicine 1984; 54: 